\title{
The Hidden Wood-Decaying Fungal Diversity: Rhizochaete from East Asia
}

\author{
Zi-Rui Gu ${ }^{1,2}$ (D) and Chang-Lin Zhao ${ }^{1,2,3,4, *(\mathbb{D})}$ \\ 1 Key Laboratory for Forest Resources Conservation and Utilization in the Southwest Mountains of China, \\ Ministry of Education, Southwest Forestry University, Kunming 650224, China; fungiziruig@126.com \\ 2 College of Biodiversity Conservation, Southwest Forestry University, Kunming 650224, China \\ 3 School of Life Sciences, Tsinghua University, Beijing 100084, China \\ 4 Yunnan Key Laboratory for Fungal Diversity and Green Development, Kunming 650201, China \\ * Correspondence: fungi@swfu.edu.cn
}

check for

updates

Citation: Gu, Z.-R.; Zhao, C.-L. The Hidden Wood-Decaying Fungal Diversity: Rhizochaete from East Asia. Diversity 2021, 13, 503. https:// doi.org/10.3390/d13100503

Academic Editor: Tine Grebenc

Received: 17 September 2021

Accepted: 11 October 2021

Published: 17 October 2021

Publisher's Note: MDPI stays neutral with regard to jurisdictional claims in published maps and institutional affiliations.

Copyright: (c) 2021 by the authors. Licensee MDPI, Basel, Switzerland. This article is an open access article distributed under the terms and conditions of the Creative Commons Attribution (CC BY) license (https:/ / creativecommons.org/licenses/by/ $4.0 /)$.

\begin{abstract}
Wood-decaying fungi play crucial roles as decomposers in forest ecosystems. In this study, two new corticioid fungi, Rhizochaete fissurata and $R$. grandinosa spp. nov., are proposed based on a combination of morphological features and molecular evidence. Rhizochaete fissurata is characterized by resupinate basidiomata with a cracking hymenial surface, a monomitic hyphal system with simple-septa generative hyphae, presence of subfusiform to conical cystidia encrusted at the apex or coarse on the upper half, and ellipsoid basidiospores. Rhizochaete grandinosa differs in its resupinate basidiomata with a smooth hymenial surface, presence of two types of cystidia, and ellipsoid basidiospores. Sequences of ITS and nLSU rRNA markers of the studied samples were employed, and phylogenetic analyses were performed with maximum likelihood, maximum parsimony, and Bayesian inference methods on two datasets (ITS+nLSU and ITS). Both dataset analyses showed that two new species clustered into the genus Rhizochaete, in which, based on the ITS $+\mathrm{nLSU}$ dataset, $R$. fissurata was sister to $R$. belizensis, and $R$. grandinosa grouped with $R$. radicata; the phylogram inferred from ITS sequences inside Rhizochaete indicated that $R$. fissurata formed a monophyletic lineage with a lower support; $R$. grandinosa grouped closely with $R$. radicata. In addition, an identification key to all Rhizochaete species worldwide is provided.
\end{abstract}

Keywords: China; corticioid fungi; diversity; Phanerochaetaceae; molecular systematics; taxonomy

\section{Introduction}

Fungi make up an under-described, poorly documented clade of eukaryotes, in which they have immense ecological and economic impacts; many fungi are microscopic or have cryptic life cycles, which makes detection difficult [1]. Based on the ratio of vascular plants and fungi in different regions, Hawksworth [2] conservatively estimated that there were 1,500,000 fungal species worldwide, with about 69,000 species known at that time, and later, Blackwell [3] indicated that fungal species numbers were estimated to be as high as $5,100,000$, with 97,861 known species. However, Hawksworth [4] proposed that the number of existing fungal species should be between 1,500,000 and 3,000,000, which is currently accepted by many mycologists $[5,6]$. Wood-decaying fungi are eukaryotic microorganisms that play fundamental ecological roles as decomposers of plants in the fungal tree of life [7], which drive carbon cycling in forest soils, mediate mineral nutrition of plants, and alleviate carbon limitations of other soil organisms [5].

Rhizochaete Gresl., Nakasone \& Rajchenb. is a small, distinctive genus of wooddecaying fungi that produces hyphal cords and has a world-wide distribution. It was typified by R. brunnea Gresl., Nakasone \& Rajchenb., and the genus is characterized by resupinate to effused, loosely adnate basidiomata of pellicular to membranous, fragile consistency, with smooth to tuberculate hymenophore covering a yellow, orange, brown, olivaceous, or violaceous hymenial surface, usually turning red to violet in $\mathrm{KOH}$ solution; 
fimbriate to fibrillose margin, often with hyphal cords; monomitic hyphal system with simple septae or clamp connections on generative hyphae; usually present cystidia; clavate to subcylindrical basidia, 4-sterigmate; cylindrical to ellipsoid basidiospores, which are thin to slightly thick-walled, smooth, acyanophilous, not reacting to Melzer's reagent; occurring on wood and bark of angiosperms and gymnosperms, associated with a white rotdecay [8]. Currently, about 14 species have been accepted in Rhizochaete worldwide [8-10]. Index Fungorum (http:/ /www.indexfungorum.org; accessed on 25 August 2021) and MycoBank (https:/ / www.mycobank.org; accessed on 25 August 2021) register 14 specific and infraspecific names in Rhizochaete.

Rhizochaete was distinguished from Phanerochaete P. Karst. by morphological and molecular characters [9], in which six species were separated from Phanerochaete and transferred to Rhizochaete. Phylogenetic studies indicated Rhizochaete in the Phanerochaete clade [11] and the Phanerochaetaceae Jülich [6]. Based on studying the parenthesome structure of some corticioid fungi, Bianchinotti et al. [12] reported that three Rhizochaete species had perforate septal dolipore caps or parenthesomes. Phylogenetic reconstruction of corticioid fungi using ITS and nLSU regions revealed that three species should be transferred to the genus Rhizochaete—R. sulphurosa (Bres.) Chikowski, K.H. Larss. \& Gibertoni, R. sulphurina (P. Karst.) K.H. Larss., and R. violascens (Fr.) K.H. Larss.-and three new combinations were made (Include reference). Floudas and Hibbett [11] revealed that Rhizochaete was monophyletic in multigene phylogenetic analyses of the Phanerochaete clade and was represented by four species. Chikowski et al. [10] resolved Rhizochaete as monophyletic in the phylogenetic analyses of ITS sequence data, which included six Rhizochaete species. On the basis of the combined ITS and nLSU analyses by Miettinen et al. [6], seven Rhizochaete species were included in a nine-way polytomy in the Phlebiopsis clade, in which Rhizochaete was resolved as a distinct subclade within the Phlebiopsis clade. Morphological studies and molecular sequence data from two nuclear ribosomal DNA regions (ITS and LSU) supported the recognition of Rhizochaete, in which R. belizensis was closely related to $R$. radicata, and three new combinations were proposed. An in-depth study of the phylogeny and taxonomy of the corticioid genus Phlebiopsis (Phanerochaetaceae) was conducted, in which Rhizochaete clustered as a sister clade to Phaeophlebiopsis and Hapalopilus, and ten species of Rhizochaete grouped together [13].

In this study, two undescribed species of wood-decaying fungi from forest ecosystems were collected in Yunnan Province, China. We present morphological and molecular phylogenetic evidence that supports the recognition of two new species in Rhizochaete based on the internal transcribed spacer ITS and nLSU sequences.

\section{Materials and Methods}

\subsection{Sample Collection and Herbarium Specimen Preparation}

Fresh fruiting bodies of the fungi growing on angiosperm stumps and trunks were collected from Dali, Puer, Wenshan, and Yuxi of Yunnan Province, China. The samples were photographed in situ, and their fresh macroscopic details were recorded. Photographs recording the bioluminescence in complete darkness were taken with a Jianeng 80D camera. All photos were focus stacked and merged using Helicon Focus software. Macroscopic details were recorded in situ. Samples were transported to a field station where the fruit bodies were dried on an electronic food dryer at $35^{\circ} \mathrm{C}$. The dried specimens were deposited in the herbarium of Southwest Forestry University (SWFC), Kunming, Yunnan Province, China.

\subsection{Morphology}

Macromorphological descriptions are based on field notes and photos captured in the field and lab. Color terminology follow Petersen [14]. Micromorphological data were obtained from the dried specimens observed under a light microscope following Dai [15]. The following abbreviations were used: $\mathrm{KOH}=5 \%$ potassium hydroxide water solution, $\mathrm{CB}=$ Cotton Blue, $\mathrm{CB}-=$ acyanophilous, $\mathrm{IKI}=$ Melzer's reagent, $\mathrm{IKI}-=$ both inamyloid 
and indextrinoid, $\mathrm{L}=$ mean spore length (arithmetic average for all spores), $\mathrm{W}=$ mean spore width (arithmetic average for all spores), $\mathrm{Q}=$ variation in the $\mathrm{L} / \mathrm{W}$ ratios between the specimens studied, and $n=a / b$ (number of spores (a) measured from given number (b) of specimens).

\subsection{Molecular Phylogeny}

The CTAB rapid plant genome extraction kit-DN14 (Aidlab Biotechnologies Co., Ltd. Beijing, China) was used to obtain genomic DNA from the dried specimens using the manufacturer's instructions (as done in [16]). The nuclear ribosomal ITS region was amplified with primers ITS5 and ITS4 [17]. The nuclear ribosomal LSU gene was amplified with primers LR0R and LR7 [18,19]. The PCR procedure for ITS was as follows: initial denaturation at $95^{\circ} \mathrm{C}$ for $3 \mathrm{~min}$, followed by 35 cycles at $94{ }^{\circ} \mathrm{C}$ for $40 \mathrm{~s}, 58^{\circ} \mathrm{C}$ for $45 \mathrm{~s}$ and $72{ }^{\circ} \mathrm{C}$ for $1 \mathrm{~min}$, and a final extension of $72{ }^{\circ} \mathrm{C}$ for $10 \mathrm{~min}$. The PCR procedure for nLSU was as follows: initial denaturation at $94{ }^{\circ} \mathrm{C}$ for $1 \mathrm{~min}$, followed by 35 cycles at $94{ }^{\circ} \mathrm{C}$ for $30 \mathrm{~s}, 48^{\circ} \mathrm{C}$ for $1 \mathrm{~min}$ and $72{ }^{\circ} \mathrm{C}$ for $1.5 \mathrm{~min}$, and a final extension of $72{ }^{\circ} \mathrm{C}$ for $10 \mathrm{~min}$. The PCR products were purified and sequenced at Kunming Tsingke Biological Technology Limited Company, Kunming, Yunnan Province, China. All newly generated sequences were deposited in NCBI GenBank (Table 1).

Sequences were aligned in MAFFT 7 (https: / / mafft.cbrc.jp/alignment/server /, accessed on 5 October 2021) using G-INS-i strategy for ITS+nLSU and ITS datasets, and they were manually adjusted in BioEdit [26]. The datasets were deposited in TreeBASE WEB (submission ID 28787). Byssomerulius corium (Pers.) Parmasto was selected as an outgroup for the phylogenetic analysis of ITS+nLSU (Figure 1), referred to following [8], and Phaeophlebiopsis caribbeana Floudas \& Hibbett was selected as an outgroup taxon in ITS phylogenetic analysis following a previous study [11].

Table 1. List of species, specimens, and GenBank accession numbers of sequences used in this study.

\begin{tabular}{|c|c|c|c|c|c|}
\hline \multirow{2}{*}{ Species Name } & \multirow{2}{*}{ Specimen No. } & \multicolumn{2}{|c|}{ GenBank Accession No. } & \multirow{2}{*}{ References } & \multirow{2}{*}{ Country } \\
\hline & & ITS & nLSU & & \\
\hline Byssomerulius corium & FP 102382 & KP135007 & KP135230 & [11] & USA, Wisconsin \\
\hline Hapalopilus eupatorii & Dammrich 10744 & KX752620 & KX752620 & [6] & Germany \\
\hline H. nidulans & JV 0206/2 & KX752623 & KX752623 & [6] & Sweden \\
\hline H. percoctus & Miettinen 2008 & KX752597 & KX752597 & [6] & Botswana \\
\hline Phanerochaete affinis & KHL 11839 & EU118652 & EU118652 & {$[20]$} & Sweden \\
\hline P. ericina & HHB 2288 & KP135167 & KP135247 & [11] & USA, North Carolina \\
\hline P. laevis & HHB 15519 & KP135149 & KP135249 & [11] & USA, Alabama \\
\hline P. rhodella & FD-18 & KP135187 & KP135258 & {$[11]$} & USA, Massachusetts \\
\hline P. velutina & LE 298547 & KP994360 & KP994385 & {$[21]$} & Russia \\
\hline $\begin{array}{c}\text { Phaeophlebiopsis } \\
\text { caribbeana }\end{array}$ & HHB-6990 & KP135415 & KP135243 & [11] & USA, Florida \\
\hline P. peniophoroides & FP 150577 & KP135417 & KP135273 & [11] & USA, Hawaii \\
\hline Phlebiopsis crassa & KKN 86 & KP135394 & KP135215 & [11] & USA, Arizona \\
\hline P. crassa & MAFF 420737 & AB809163 & AB809163 & [22] & Japan \\
\hline P. flavidoalba & KHL 13055 & EU118662 & EU118662 & [20] & Costa Rica \\
\hline P. gigantea & FBCC 315 & LN611131 & LN611131 & [23] & Sweden \\
\hline Rhizochaete americana & FP-102188 & KP135409 & KP135277 & [11] & USA, Illinois \\
\hline R. americana & HНB 2004 & AY219391 & AY219391 & [9] & USA, Georgia \\
\hline R. belizensis & FP 150712 & KP135408 & KP135280 & [11] & Belize \\
\hline R. borneensis & WEI 16-426 & MZ637070 & MZ637270 & Unpublished & China \\
\hline R. brunnea & MR 11455 & AY219389 & AY219389 & [9] & Argentina \\
\hline R. filamentosa & FP 105240 & KP135411 & AY219393 & [8] & USA, Indiana \\
\hline R. filamentosa & HНB 3169 & KP135410 & KP135278 & [11] & USA, Maryland \\
\hline R. fissurata & CLZhao 2200 & MZ713640 & MZ713844 & Present study & China \\
\hline R. fissurata & CLZhao 7965 & MZ713641 & MZ713845 & Present study & China \\
\hline R. fissurata & CLZhao 10407 & MZ713642 & MZ713846 & Present study & China \\
\hline
\end{tabular}


Table 1. Cont.

\begin{tabular}{|c|c|c|c|c|c|}
\hline \multirow{2}{*}{ Species Name } & \multirow{2}{*}{ Specimen No. } & \multicolumn{2}{|c|}{ GenBank Accession No. } & \multirow{2}{*}{ References } & \multirow{2}{*}{ Country } \\
\hline & & ITS & nLSU & & \\
\hline R. fissurata & CLZhao 10418 & MZ713643 & MZ713847 & Present study & China \\
\hline R. flava & PR 1141 & KY273030 & KY273033 & [8] & Puerto Rico \\
\hline R. flava & PR 3148 & KY273029 & - & {$[8]$} & Puerto Rico \\
\hline R. fouquieriae & KKN 121 & AY219390 & GU187608 & [8] & USA, Arizona \\
\hline R. fouquieriae & KKN-121-sp & KY948786 & KY948858 & [24] & United States \\
\hline R. grandinosa & CLZhao 3117 & MZ713644 & MZ713848 & Present study & China \\
\hline R. radicata & FD 123 & KP135407 & KP135279 & [11] & USA, Massachusetts \\
\hline R. radicata & FD 338 & KP135406 & - & [11] & USA, Massachusetts \\
\hline R. radicata & НHВ 1909 & AY219392 & AY219392 & [9] & USA, North Carolina \\
\hline R. rubescens & Wu 0910-45 & LC387335 & MF110294 & [25] & China \\
\hline R. sulphurina & DLL 2014-176 & KY273032 & - & [8] & USA, Idaho \\
\hline R. sulphurina & HHB 5604 & KY273031 & GU187610 & [8] & USA, Montana \\
\hline R. sulphurosa & KHL 16087 & КТ003523 & - & [10] & Brazil \\
\hline R. sulphurosa & URM 87190 & КT003522 & КT003519 & [10] & Brazil \\
\hline
\end{tabular}

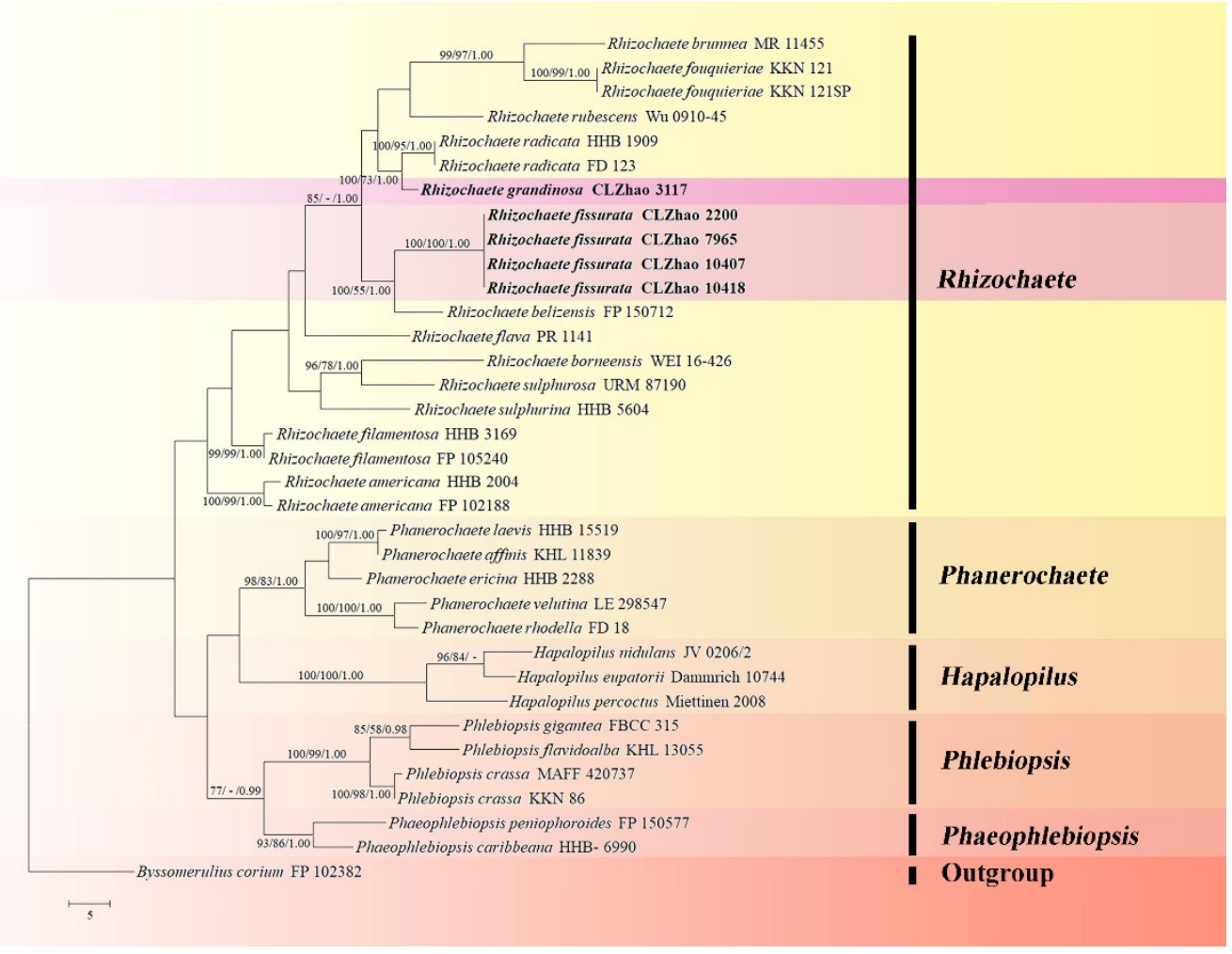

Figure 1. Maximum parsimony strict consensus tree illustrating the phylogeny of the two new species and related species within the family Phanerochaetaceae based on ITS+nLSU sequences. Branches are labeled with maximum likelihood bootstrap values $>70 \%$, parsimony bootstrap values $>50 \%$, and Bayesian posterior probabilities $>0.95$, respectively.

Maximum parsimony analysis was applied to the combined ITS+nLSU and ITS datasets. The approach followed the previous study by Zhao and $\mathrm{Wu}$ [16], and the tree construction procedure was performed in PAUP* version 4.0a169 (http:/ / phylosolutions. $\mathrm{com} /$ paup-test/, accessed on 5 October 2021). All characters were equally weighted, and gaps were treated as missing data. Trees were inferred using the heuristic search option with TBR branch swapping and 1000 random sequence additions. Max-trees were set to 5000 , branches of zero length were collapsed, and all parsimonious trees were saved. Clade robustness was assessed using bootstrap (BT) analysis with 1000 replicates [27]. Descriptive tree statistics - tree length (TL), consistency index (CI), retention index (RI), 
rescaled consistency index (RC), and homoplasy index (HI) - were calculated for each maximum parsimonious tree generated. The combined dataset was also analyzed using maximum likelihood (ML) in RAxML-HPC2 through the Cipres Science Gateway [28]. Branch support (BS) for ML analysis was determined by 1000 bootstrap replicates.

MrModeltest 2.3 [29] was used to determine the best-fit evolution model for each dataset (ITS $+n L S U$ and ITS) for Bayesian inference (BI). BI was calculated with MrBayes version 3.2.7a [30]. Four Markov chains were run for 2 runs from random starting trees for 250 thousand generations for ITS+nLSU (Figure 1) and 200 thousand generations for ITS (Figure 2). The first one-fourth of all generations was discarded as burn-in. The majority rule consensus tree of all remaining trees was calculated. Branches were considered as significantly supported if they received maximum likelihood bootstrap value (BS) $>70 \%$, maximum parsimony bootstrap value $(\mathrm{BT})>70 \%$, or Bayesian posterior probabilities $(\mathrm{BPP})>0.95$.

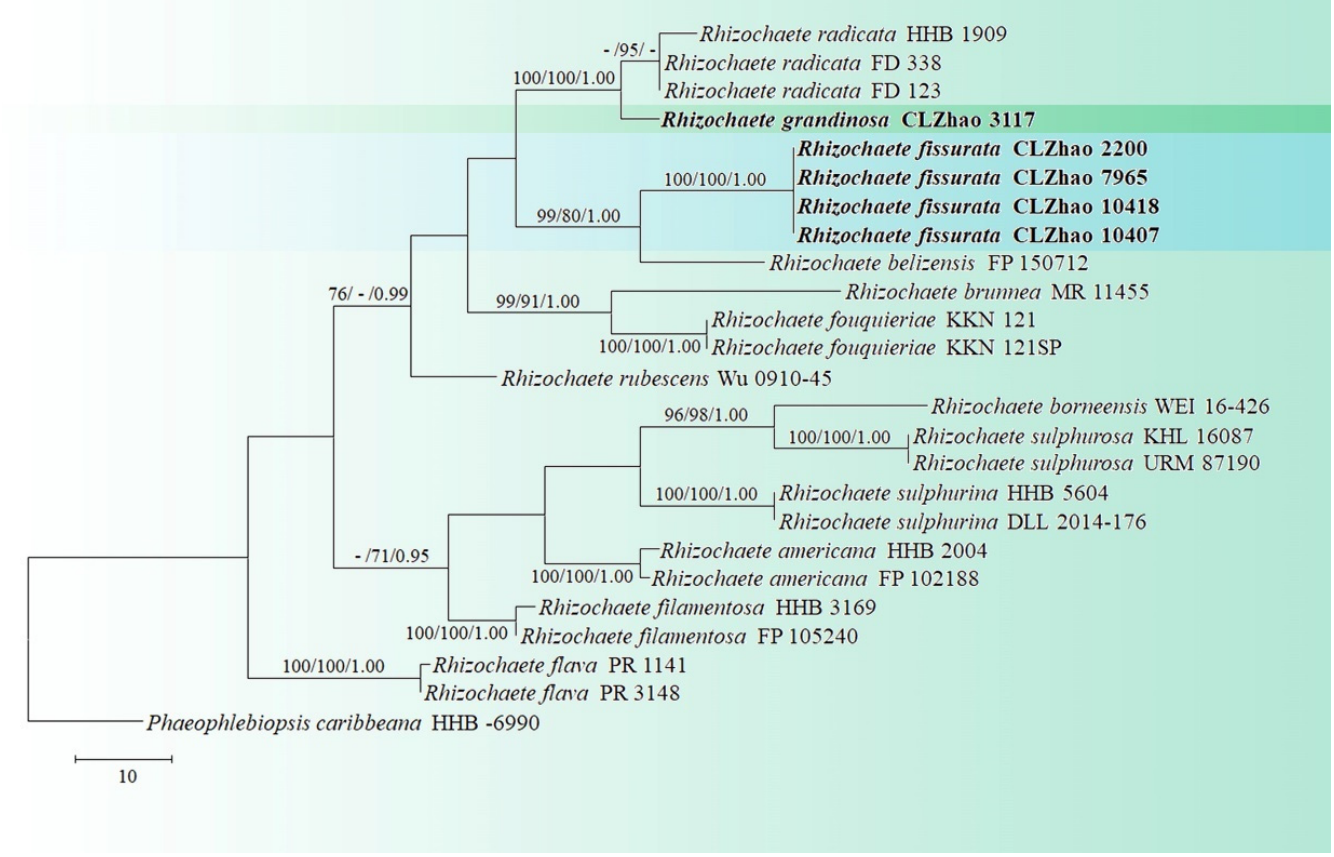

Figure 2. Maximum parsimony strict consensus tree illustrating the phylogeny of the two new species and related species in Rhizochaete based on ITS sequences. Branches are labeled with maximum likelihood bootstrap values $>70 \%$, parsimony bootstrap values $>50 \%$, and Bayesian posterior probabilities $>0.95$, respectively.

\section{Results}

\subsection{Molecular Phylogeny}

The ITS+nLSU dataset (Figure 1) included sequences from 35 fungal specimens representing 27 taxa. The dataset had an aligned length of 738 characters, of which 388 characters are constant, 99 are variable and parsimony-uninformative, and 251 are parsimony-informative. Maximum parsimony analysis yielded 61 equally parsimonious trees $(\mathrm{TL}=412, \mathrm{CI}=0.4733, \mathrm{HI}=0.5267, \mathrm{RI}=0.6146$, and $\mathrm{RC}=0.2909)$. The best model for the ITS+nLSU dataset estimated and applied in the Bayesian analysis was GTR+I+G. Bayesian analysis and ML analysis resulted in a similar topology as in the MP analysis with an average standard deviation of split frequencies $=0.009664$ (BI). The phylogram inferred from ITS+nLSU sequences within family Phanerochaetaceae highlighted two undescribed species nested in genus Rhizochaete, in which $R$. fissurata was sister to R. belizensis Nakasone, K. Draeger \& B. Ortiz with a medium supported lineage (99\% BS, 79\% BP and 1.00 BPP); R. grandinosa grouped with R. radicata (Henn.) Gresl., Nakasone \& Rajchenb. (100\% BS, 99\% $\mathrm{BP}$ and $1.00 \mathrm{BPP})$. 
The ITS-alone dataset (Figure 2) included sequences from 25 fungal specimens representing 13 taxa. The dataset had an aligned length of 728 characters, of which 459 characters are constant, 62 are variable and parsimony-uninformative, and 207 are parsimonyinformative. Maximum parsimony analysis yielded 18 equally parsimonious trees (TL = 334, $\mathrm{CI}=0.5749, \mathrm{HI}=0.4251, \mathrm{RI}=0.7380$, and $\mathrm{RC}=0.4242)$. The best model for the ITS dataset estimated and applied in the Bayesian analysis was GTR+I+G. Bayesian analysis and ML analysis resulted in a similar topology as in the MP analysis with an average standard deviation of split frequencies $=0.008927(\mathrm{BI})$. The phylogram inferred from ITS sequences within genus Rhizochaete revealed that $R$. fissurata formed a monophyletic lineage with a lower support; $R$. grandinosa grouped closely with $R$. radicata.

\subsection{Taxonomy}

Rhizochaete fissurata C.L. Zhao sp. nov. Figures 3 and 4.
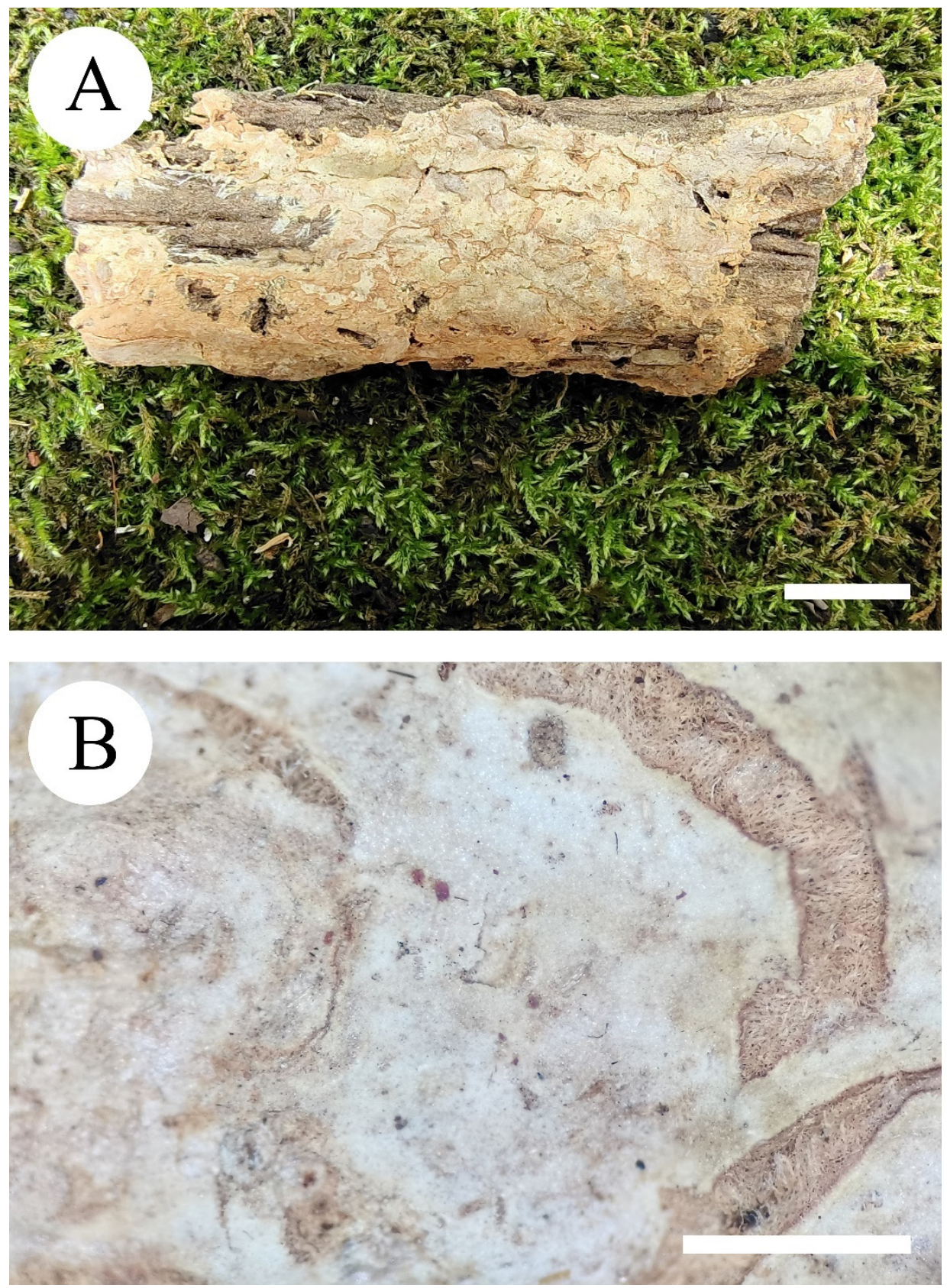

Figure 3. Basidiomata of Rhizochaete fissurata (holotype). Bars: $(\mathbf{A})=1 \mathrm{~cm}$ and $(\mathbf{B})=1 \mathrm{~mm}$. 

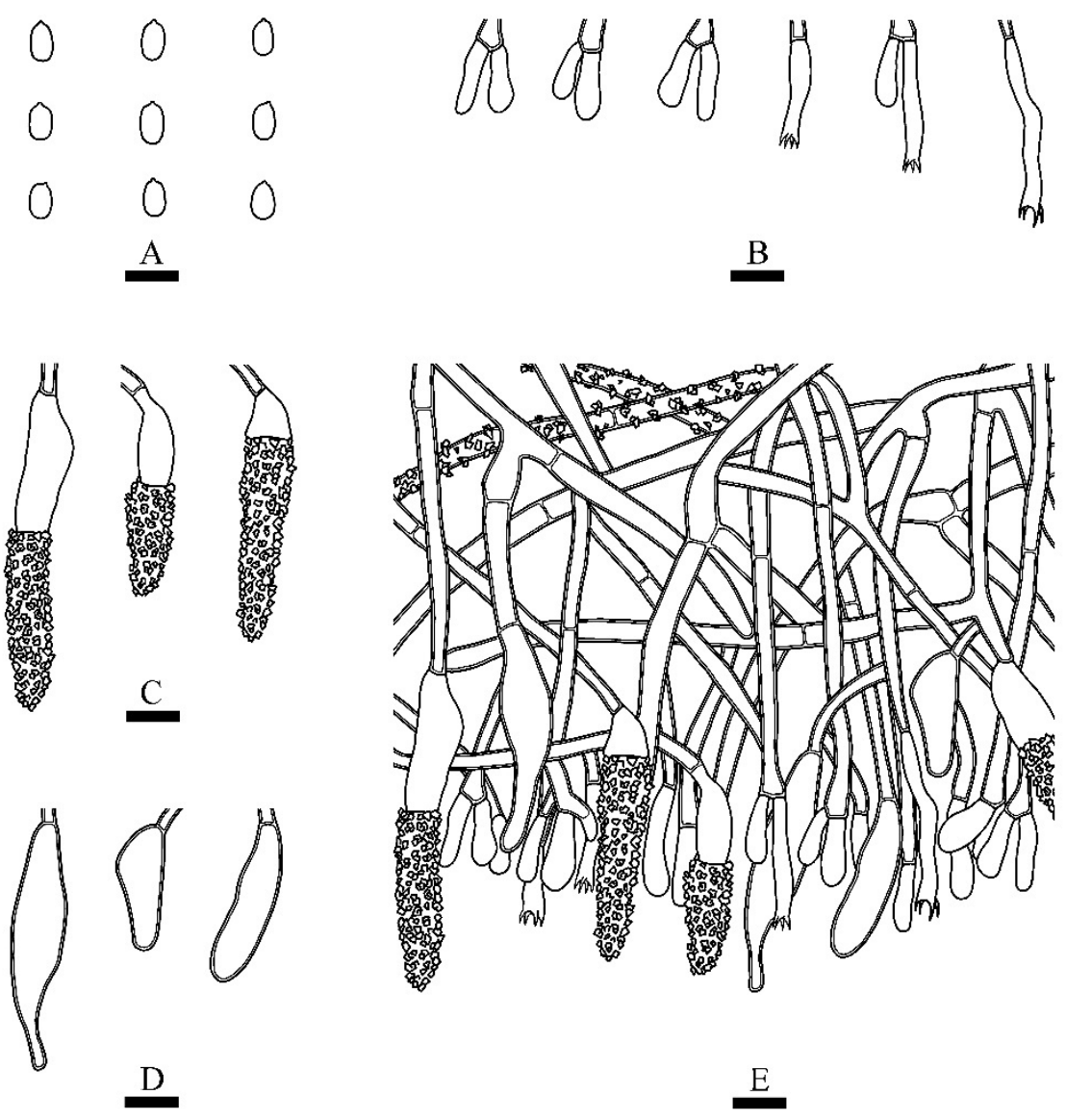

Figure 4. Microscopic structures of Rhizochaete fissurata (holotype): (A) basidiospores; (B) basidia and basidioles; (C,D) cystidia; (E) a section of hymenium. Bars: $(\mathbf{A})=5 \mu \mathrm{m},(\mathbf{B}-\mathbf{E})=10 \mu \mathrm{m}$.

MycoBank no.: 841215

Holotype-China. Yunnan Province, Dali, Nanjian County, Lingbaoshan National Forestry Park, GPS co-ordinates $24^{\circ} 44^{\prime} \mathrm{N}, 100^{\circ} 29^{\prime} \mathrm{E}$, altitude $2300 \mathrm{~m}$ asl., on an angiosperm trunk, leg. C.L. Zhao, 10 January 2019, CLZhao 10,407 (SWFC).

Etymology_fissurata (Lat.): referring to the cracking hymenial surface.

Fruiting body-Basidiomata annual, resupinate, loosely adnate, soft, membranous to pellicular, without odor and taste when fresh, up to $10 \mathrm{~cm}$ long, $3 \mathrm{~cm}$ wide, 500-900 $\mu \mathrm{m}$ thick, violet in $\mathrm{KOH}$. Hymenial surface smooth, obviously cracking, buff to olivaceous buff when fresh, olivaceous buff to pale brown on drying. Margin sterile, thinning out, narrow, cream. Hyphal cords fimbriate.

Hyphal system-Monomitic, generative hyphae having simple septa, colorless, thinwalled, frequently branched, interwoven, 2-7 $\mu \mathrm{m}$ in diameter; IKI-, CB-; tissues unchanged in $\mathrm{KOH}$; subhymenial hyphae sometimes densely covered with crystals.

Hymenium-Cystidia numerous, subfusiform to conical, slightly thick-walled, $<1 \mu \mathrm{m}$ thick, encrusted at the apex or with coarse upper half, $18-60.5 \times 6-11 \mu \mathrm{m}$; basidia cylindrical, slightly constricted in the middle to somewhat sinuous, with four sterigmata and simple septa, $11-33 \times 3-5 \mu \mathrm{m}$.

Spores-Basidiospores ellipsoid, colorless, thin-walled, smooth, IKI-, CB-, 3-4.5 $\times$ (2-)2.5-3 $\mu \mathrm{m}, \mathrm{L}=3.68 \mu \mathrm{m}, \mathrm{W}=2.74 \mu \mathrm{m}, \mathrm{Q}=1.23-1.51$ ( $\mathrm{n}=120 / 4)$.

Additional specimens examined-China. Yunnan Province, Yuxi, Xinping County, Mopanshan National Forestry Park, GPS co-ordinates $23^{\circ} 46^{\prime} \mathrm{N}, 101^{\circ} 16^{\prime} \mathrm{E}$, altitude $2214 \mathrm{~m}$ asl., on an angiosperm trunk, leg. C.L. Zhao, 18 August 2017, CLZhao 2200 (SWFC); altitude $2322 \mathrm{~m}$ asl., on an angiosperm trunk, leg. C.L. Zhao, 19 August 2018, CLZhao 7965 (SWFC); Dali, Nanjian County, Lingbaoshan National Forestry Park, GPS co-ordinates $24^{\circ} 44^{\prime} \mathrm{N}$, 
$100^{\circ} 29^{\prime} \mathrm{E}$, altitude $2300 \mathrm{~m}$ asl., on an angiosperm stump, leg. C.L. Zhao, 10 January 2019, CLZhao 10,418 (SWFC).

Habitat and ecology —Climate of the sample collection site is monsoon humid, the forest type is evergreen broad-leaved forest, and samples were collected on an angiosperm trunk.

Rhizochaete grandinosa C.L. Zhao \& Z.R. Gu, sp. nov. Figures 5 and 6.

MycoBank no.: 841216

Holotype-China. Yunnan Province, Puer, Laiyanghe National Forestry Park, GPS co-ordinates $22^{\circ} 36^{\prime} \mathrm{N}, 101^{\circ} 1^{\prime} \mathrm{E}$, altitude $1500 \mathrm{~m}$ asl., on an angiosperm trunk, leg. C.L. Zhao, 30 September 2017, CLZhao 3117 (SWFC).

Etymology—grandinosa (Lat.): referring to the grand nose or protrusion of the basidiomata.
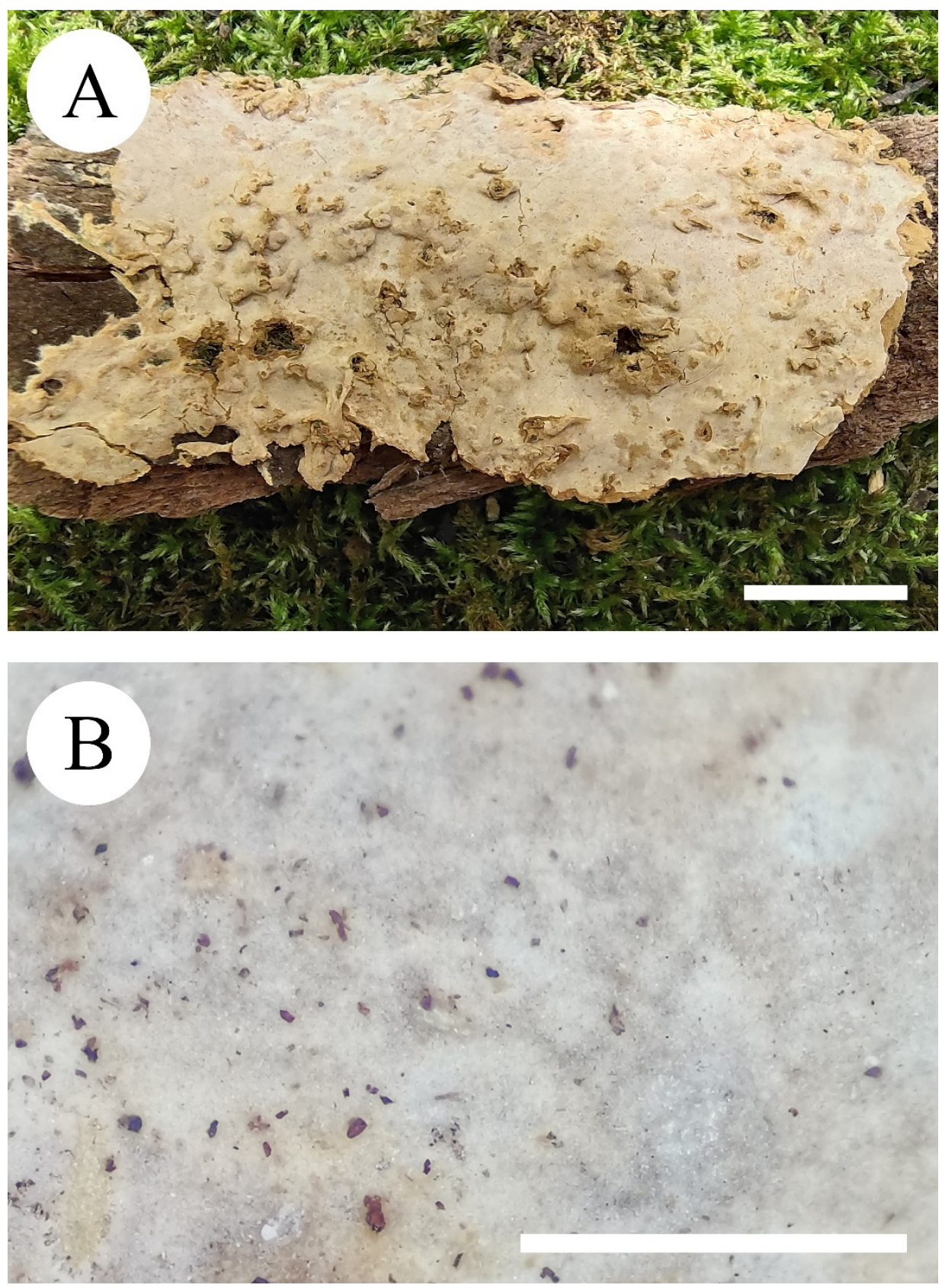

Figure 5. Basidiomata of Rhizochaete grandinosa (holotype). Bars: $(\mathbf{A})=1 \mathrm{~cm}$ and $(\mathbf{B})=1 \mathrm{~mm}$. 

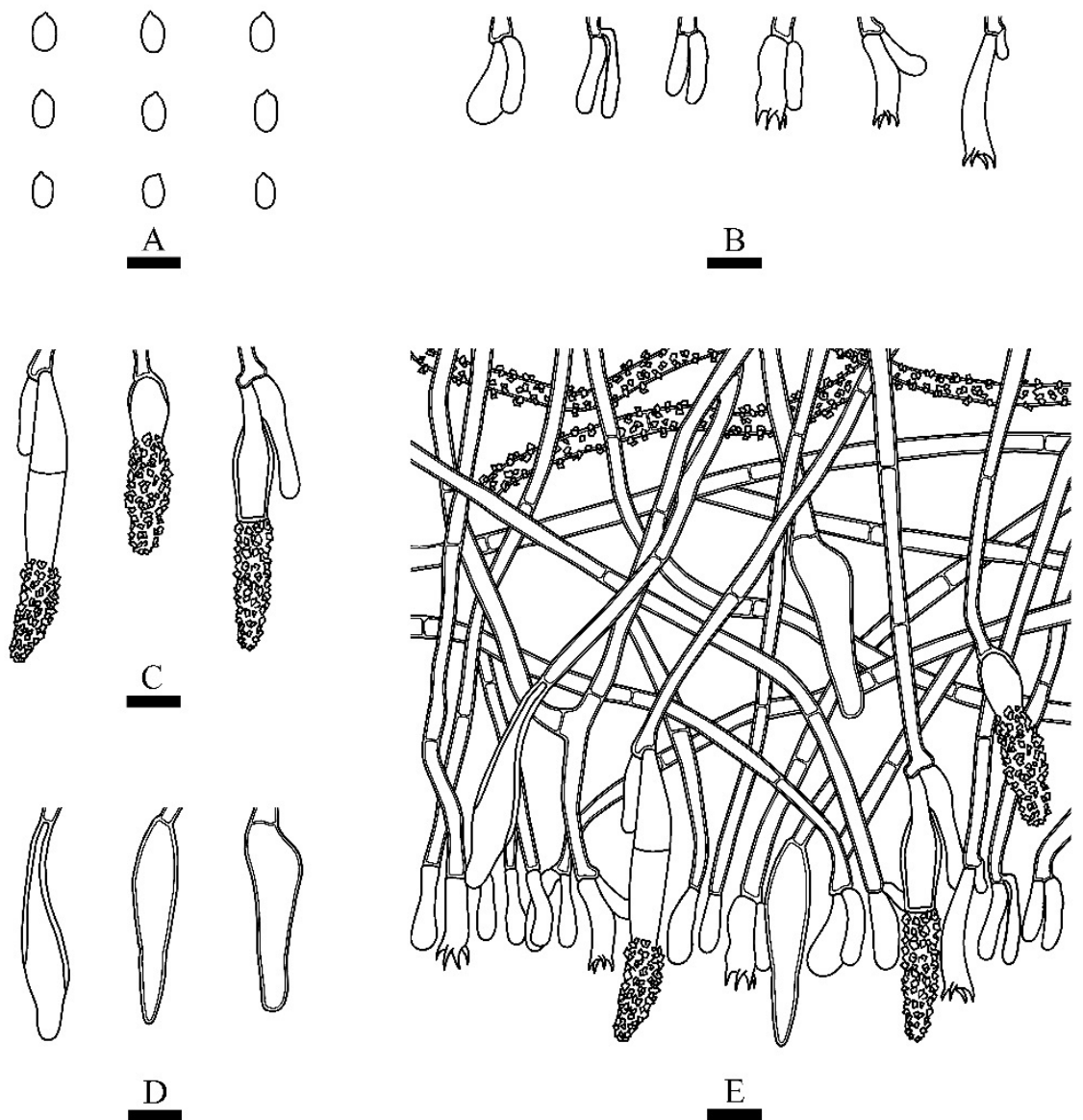

Figure 6. Microscopic structures of Rhizochaete grandinosa (holotype): (A) basidiospores; (B) basidia and basidioles; (C,D) cystidia; (E) a section of hymenium. Bars: $(\mathbf{A})=5 \mu \mathrm{m},(\mathbf{B}-\mathbf{E})=10 \mu \mathrm{m}$.

Fruiting body-Basidiomata annual, resupinate, loosely adnate, soft, membranous when fresh, cottony upon drying, up to $9 \mathrm{~cm}$ long, $4.5 \mathrm{~cm}$ wide, 300-500 $\mu \mathrm{m}$ thick, violet in $\mathrm{KOH}$. Hymenial surface smooth, with grand nose or protrusion, curry-yellow when fresh, curry-yellow to cinnamon-buff upon drying. Margin sterile, slightly brown, $1 \mathrm{~mm}$ wide. Hyphal cords fimbriate.

Hyphal system-Monomitic, generative hyphae with simple septa, colorless, thickwalled, rarely branched, interwoven, 3-6 $\mu \mathrm{m}$ in diameter, IKI-, CB-; tissues unchanged in $\mathrm{KOH}$.

Hymenium-Cystidia numerous, colorless, subfusiform to conical with an obtuse apex, simple septa at base, protruding or enclosed, sometimes with secondary septa, thin to slightly thick-walled, $<1 \mu \mathrm{m}$ thick, upper half lightly to heavily encrusted with hyaline, insoluble crystals, $24-50 \times 4-9 \mu \mathrm{m}$; basidia clavate to subcylindrical, constricted, somewhat sinuous, with four sterigmata and simple septa, $14.5-21 \times 4.3-5.2 \mu \mathrm{m}$.

Spores-Basidiospores ellipsoid, colorless, thin-walled, smooth, IKI-, CB-, 3-4(-4.5) $\times 2.5-3(-3.3) \mu \mathrm{m}, \mathrm{L}=3.65 \mu \mathrm{m}, \mathrm{W}=2.79 \mu \mathrm{m}, \mathrm{Q}=1.31(\mathrm{n}=30 / 1)$.

Habitat and ecology-Climate of the sample collection site is a transition between tropical and subtropical climate, the forest type is tropical monsoon evergreen broad-leaved forest, and samples were collected on an angiosperm trunk.

\section{Discussion}

In the present study, two new species, Rhizochaete fissurata and R. grandinosa, are described based on phylogenetic analyses and morphological characters.

A revised family-level classification of Polyporales (Basidiomycota) using nrLSU, nrITS, and rpb1 genes across Polyporales showed that the genus Rhizochaete nested into 
family Phanerochaetaceae, in which Rhizochaete was grouped with Phlebiopsis, Phaeophlebiopsis, and Hapalopilus [24]. In the present study, all species of the Rhizochaete group together and the genus cluster with a sister clade comprising Phlebiopsis and Phaeophlebiopsis.

Phylogenetically, the two new taxa were found to group into genus Rhizochaete based on the ITS $+\mathrm{nLSU}$ dataset, in which $R$. fissurata was sister to $R$. belizensis; $R$. grandinosa was grouped with $R$. radicata (Figure 1). Based on the ITS dataset, $R$. fissurata formed a monophyletic lineage; $R$. grandinosa grouped closely with $R$. radicata (Figure 2). However, morphologically, R. belizensis Nakasone, K. Draeger \& B. Ortiz differs from R. fissurata by having the orange white to violaceous hymenial surface and generative hyphae with rare single clamps [8]; $R$. radicata differs from $R$. grandinosa by its yellowish buff to ochraceous hymenial surface, becoming reddish purple in $\mathrm{KOH}$, and by larger basidiospores $(4-5 \times 2.5-3 \mu \mathrm{m})$ [31].

Morphologically, Rhizochaete fissurata is similar to R. brunnea and R. sulphurosa in the hymenium turning violet in $\mathrm{KOH}$. However, $R$. brunnea differs by its larger cystidia $(100-250 \times 8-15 \mu \mathrm{m})$ [9]; $R$. sulphurosa is separated from $R$. fissurata by having the lemon yellow to mustard to buff hymenial surface and larger basidiospores $(4.5-5.5 \times 2-3 \mu \mathrm{m})[10]$.

Rhizochaete fissurata is similar to R. filamentosa (Berk. \& M.A. Curtis) Gresl., Nakasone \& Rajchenb. and R. percitrina (P. Roberts \& Hjortstam) Nakasone in having the simplesepta generative hyphae. However, $R$. filamentosa differs from $R$. fissurata by its orangegray to brownish orange basidiomata and larger basidiospores $(4.5-5.5 \times 2-2.5 \mu \mathrm{m})$ [32]; R. percitrina differs in its smooth to farinaceous hymenial surface with no change in $\mathrm{KOH}$, and narrower cystidia $(22-35 \times 3.5-6 \mu \mathrm{m})$ [8].

Rhizochaete grandinosa is similar to R. americana (Nakasone, C.R. Bergman \& Burds.) Gresl., Nakasone \& Rajchenb., R. rhizomorphosulphurea (B.K. Bakshi \& Suj. Singh) Nakasone, and $R$. rubescens (Sheng $\mathrm{H}$. Wu) Sheng $\mathrm{H}$. Wu in having the thick-walled, encrusted cystidia. However, R. americana differs from $R$. grandinosa by its greyish brown to yellowish brown hymenial surface and larger basidia $(22-36 \times 4-5 \mu \mathrm{m})$ [31]; $R$. rhizomorphosulphurea differs from $R$. grandinosa by having the widely effused basidiomata, with sulfur yellow to light orange hymenial surface and larger basidiospores $(4-4.5 \times 2.8-3.6 \mu \mathrm{m})$ [8]; R. rubescens differs in its hymenial surface reddening in $\mathrm{KOH}$ and generative hyphae rarely clamped [33].

Rhizochaete species are worldwide distributed (e.g., America, Argentina, Belize, Borneo, Brazil, Burundi, Cameroon, Canada, China, Costa Rica, Cuba, Denmark, Finland, Germany, India, Jamaica, Japan, Mexico, New Zealand, Norway, Sweden, Switzerland, Uganda, Vietnam) and are mainly found on angiosperm bark and wood. Wood-decaying taxa were widely collected and studied from China [34-38], in which three Rhizochaete species$R$. filamentosa, R. rubescens, and R. sulphurina-were reported [39]. Further studies should focus on the relationships between Rhizochaete species and their hosts as well as trying to better understand the evolutionary directions between hosts and Rhizochaete species.

\section{Key to all species of Rhizochaete worldwide}

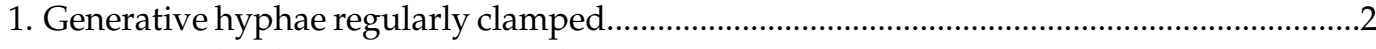

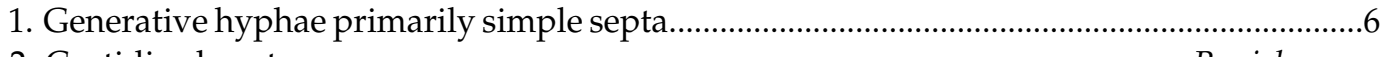

2. Cystidia absent................................................................................................... violascens

2. Cystidia abundant......................................................................................................

3. Cystidia up to $250 \mu \mathrm{m}$ long with thick walls, basidia $>40 \mu \mathrm{m}$ in length................. . brunnea

3. Cystidia up to $100 \mu \mathrm{m}$ long with thin walls, basidia $<40 \mu \mathrm{m}$ in length...................................

4. Basidiospores $>3 \mu \mathrm{m}$ in width........................................................................ fouquieriae

4. Basidiospores $<3 \mu \mathrm{m}$ in width...........................................................................................

5. Basidiomes olive brown to yellowish brown, cystidia $<60 \mu \mathrm{m}$ in length.........R. americana

5. Basidiomes bright to dull yellow, cystidia $>60 \mu \mathrm{m}$ in length............................ sulphurina

6. Cystidia with thin or slightly thickened walls, $<1 \mu \mathrm{m}$ thick ................................................

6. Cystidia with distinctly thick walls, $>1 \mu \mathrm{m}$ thick ................................................................

7. Hymenium turning violet or red in $\mathrm{KOH}$.....................................................................

7. Hymenium not reacting or changing to orange or brown in $\mathrm{KOH}$......................................12 
8. Hymenium turning red in $\mathrm{KOH}$. .9

8. Hymenium turning violet in $\mathrm{KOH}$ 10

9. Subiculum brown. R. filamentosa

9. Subiculum colorless. R. rubescens

10. Subiculum yellow.. R. sulphurosa

10. Subiculum colorless ...11

11. Hymenial surface smooth, cracking. R. fissurata

11. Hymenial surface grandinioid, not cracking..... R. grandinosa

12. Basidiomes bright yellow, unchanged in $\mathrm{KOH}$ R. percitrina

12. Basidiomes yellow to brownish orange, darkening in $\mathrm{KOH}$. .13

13. Basidia $>30 \mu \mathrm{m}$ in length

13. Basidia $<30 \mu \mathrm{m}$ in length.

14. Cystidia $<50 \mu \mathrm{m}$ in length

14. Cystidia $>50 \mu \mathrm{m}$ in length. R. rhizomorphosulphurea in length . borneensis .R. radicata

15. Subiculum yellow, cystidia $<60 \mu \mathrm{m}$ in length, basidiospores $<4 \mu \mathrm{m}$ in length..

R. belizensis

Author Contributions: Conceptualization, C.-L.Z.; methodology, C.-L.Z. and Z.-R.G.; software, C.-L.Z. and Z.-R.G.; validation, C.-L.Z. and Z.-R.G.; formal analysis, C.-L.Z. and Z.-R.G.; investigation, C.-L.Z. and Z.-R.G.; resources, C.-L.Z.; writing-original draft preparation, C.-L.Z. and Z.-R.G.; writing-review and editing, C.-L.Z. and Z.-R.G.; visualization, C.-L.Z. and Z.-R.G.; supervision, C.-L.Z.; project administration, C.-L.Z.; funding acquisition, C.-L.Z. All authors have read and agreed to the published version of the manuscript.

Funding: The research was supported by the Yunnan Fundamental Research Project (Grant No. 202001AS070043) and the High-level Talents Program of Yunnan Province (YNQR-QNRC-2018-111).

Institutional Review Board Statement: Not applicable for studies not involving humans or animals. Informed Consent Statement: Not applicable for studies not involving humans.

Data Availability Statement: Publicly available datasets were analyzed in this study. These data can be found here: https:/ /www.ncbi.nlm.nih.gov/; https://www.mycobank.org/page/Simple\%20names\% 20search; http:/ / purl.org/phylo/treebase, submission ID 28787; (accessed on: 17 September 2021).

Conflicts of Interest: The authors declare no conflict of interest.

\section{References}

1. Hibbett, D.; Abarenkov, A.; Kõljalg, U.; Öpik, M.; Chai, B.; Cole, J.; Crous, P.; Robert, V.; Helgason, T.; Herr, J.R.; et al. Sequencebased classification and identification of Fungi. Mycologia 2016, 108, 1049-1068. [CrossRef]

2. Hawksworth, D. The fungal dimension of biodiversity: Magnitude, significance, and conservation. Mycol. Res. 1991, 95, 641-655. [CrossRef]

3. Blackwell, M. The fungi: 1, 2, 3 . . 5.1 million species? Botany 2011, 98, 426-438. [CrossRef] [PubMed]

4. Hawksworth, D. Global species numbers of fungi: Are tropical studies and molecular approaches contributing to a more robust estimate? Biodivers. Conserv. 2012, 21, 2425-2433. [CrossRef]

5. Tedersoo, L.; Bahram, M.; Põlme, S.; Kõljalg, U.; Yorou, N.S.; Wijesundera, R.; Ruiz, L.V.; Vasco-Palacios, A.M.; Thu, P.Q.; Suija, A.; et al. Global diversity and geography of soil fungi. Science 2014, 346, 1256688. [CrossRef] [PubMed]

6. Miettinen, O.; Spirin, V.; Vlasak, J.; Rivoire, B.; Stenroos, S.; Hibbett, D.S. Polypores and genus concepts in Phanerochaetaceae (Polyporales, Basidiomycota). Mycokeys 2016, 17, 1-46. [CrossRef]

7. James, T.Y.; Stajich, J.E.; Hittinger, C.T.; Rokas, A. Toward a fully resolved fungal tree of life. Annu. Rev. Microbiol. 2020, 74, 291-313. [CrossRef]

8. Nakasone, K.K.; Draeger, K.R.; Ortiz-Santana, B. A contribution to the taxonomy of Rhizochaete (Polyporales, Basidiomycota). Cryptogam. Mycol. 2017, 38, 81-99. [CrossRef]

9. Greslebin, A.; Nakasone, K.K.; Rajchenberg, M. Rhizochaete, a new genus of phanerochaetoid fungi. Mycologia 2004, 96, 260-271. [CrossRef]

10. Chikowski, R.S.; Larsson, K.H.; Gibertoni, T.B. Three new combinations in Rhizochaete (Agaricomycetes, Fungi) and a new record to the Brazilian Amazonia. Nova Hedwig. 2016, 102, 185-196. [CrossRef] 
11. Floudas, D.; Hibbett, D.S. Revisiting the taxonomy of Phanerochaete (Polyporales, Basidiomycota) using a four gene dataset and extensive ITS sampling. Fungal Biol. 2015, 119, 679-719. [CrossRef]

12. Bianchinotti, M.V.; Rajchenberg, M.; Greslebin, A.G. Parenthesome structure of some corticioid fungi. Mycol. Res. 2005, 109, 923-926. [CrossRef] [PubMed]

13. Zhao, Y.N.; He, S.H.; Nakasone, K.K.; Kumara, K.L.W.; Chen, C.C.; Liu, S.L.; Ma, H.X.; Huang, M.R. Global phylogeny and taxonomy of the wood-decaying fungal genus Phlebiopsis (Polyporales, Basidiomycota). Front. Microbiol. 2021, 12, 622460. [CrossRef] [PubMed]

14. Petersen, J.H. Farvekort. The Danish Mycological Society's Colour-Chart; Foreningen til Svampekundskabens Fremme: Greve, Danmark, 1996.

15. Dai, Y.C. Polypore diversity in China with an annotated checklist of Chinese polypores. Mycoscience 2012, 53, 49-80. [CrossRef]

16. Zhao, C.L.; Wu, Z.Q. Ceriporiopsis kunmingensis sp. nov. (Polyporales, Basidiomycota) evidenced by morphological characters and phylogenetic analysis. Mycol. Prog. 2017, 16, 93-100. [CrossRef]

17. White, T.J.; Bruns, T.; Lee, S.; Taylor, J. Amplification and direct sequencing of fungal ribosomal RNA genes for phylogenetics. PCR Protoc. A Guide Methods Appl. 1990, 18, 315-322. [CrossRef]

18. Vilgalys, R.; Hester, M. Rapid genetic identification and mapping of enzymatically amplified ribosomal DNA from several Cryptococcus species. Bacteriology 1990, 172, 4238-4246. [CrossRef] [PubMed]

19. Rehner, S.A.; Samuels, G.J. Taxonomy and phylogeny of Gliocladium analysed from nuclear large subunit ribosomal DNA sequences. Mycol. Res. 1994, 98, 625-634. [CrossRef]

20. Larsson, K.H. Re-thinking the classification of corticioid fungi. Mycol. Res. 2007, 111, 1040-1063. [CrossRef]

21. Volobuev, S.; Okun, M.; Ordynets, A.; Spirin, V. The Phanerochaete sordida group (Polyporales, Basidiomycota) in temperate Eurasia, with a note on Phanerochaete pallida. Mycol. Prog. 2015, 14, 80. [CrossRef]

22. Takano, M.; Abe, H.; Hayashi, N. Extracellular peroxidase activity at the hyphal tips of the white-rot fungus Phanerochaete crassa WD1694. Wood Sci. 2006, 52, 429-435. [CrossRef]

23. Kuuskeri, J.; Mäkelä, M.R.; Isotalo, J.; Oksanen, L.; Lundell, T. Lignocellulose-converting enzyme activity profiles correlate with molecular systematics and phylogeny grouping in the incoherent genus Phlebia (Polyporales, Basidiomycota). BMC Microbiol. 2015, 15, 217. [CrossRef] [PubMed]

24. Justo, A.; Miettinen, O.; Floudas, D.; Ortiz-Santana, B.; Sjokvist, E.; Lindner, D.; Nakasone, K.K.; Niemela, T.; Larsson, K.H.; Ryvarden, L.; et al. A revised family-level classification of the Polyporales (Basidiomycota). Fungal Biol. 2017, 121, 798-824. [CrossRef] [PubMed]

25. Chen, C.C.; Wu, S.H.; Chen, C.Y. Hydnophanerochaete and Odontoefibula, two new genera of phanerochaetoid fungi (Polyporales, Basidiomycota) from East Asia. MycoKeys 2018, 39, 75-96. [CrossRef]

26. Hall, T.A. Bioedit: A user-friendly biological sequence alignment editor and analysis program for windows $95 / 98 /$ NT. Nucleic Acids Symp. Ser. 1999, 41, 95-98.

27. Felsenstein, J. Confidence intervals on phylogenetics: An approach using bootstrap. Evolution 1985, 39, 783-791. [CrossRef]

28. Miller, M.A.; Pfeiffer, W.; Schwartz, T. The CIPRES Science Gateway: Enabling High-Impact Science for Phylogenetics Researchers with Limited Resources. Assoc. Comput. Mach. 2012, 39, 1-8. [CrossRef]

29. Nylander, J.A.A. MrModeltest v2. Program Distributed by the Author; Evolutionary Biology Centre, Uppsala University: Uppsala, Sweden, 2004.

30. Ronquist, F.; Teslenko, M.; van der Mark, P.; Ayres, D.L.; Darling, A.; Hohna, S.; Larget, B.; Liu, L.; Suchard, M.A.; Huelsenbeck, J.P. Mrbayes 3.2, Efficient bayesian phylogenetic inference and model choice across a large model space. Syst. Biol. 2012, 61, 539-542. [CrossRef]

31. Nakasone, K.K.; Bergman, C.R.; Burdsall Jr, H.H. Phanerochaete filamentosa-Corticium radicatum Species Complex in North America. Sydowia 1994, 46, 44-62.

32. Burdsall Jr, H.H. Taxonomic and distributional notes on Corticiaceae (Homobasidiomycetes, Aphyllophorales) of the southern appalachians. Algae Fungi 1975, 265-286.

33. Wu, S.H. Nine new species of Phanerochaete from Taiwan. Mycol. Res. 1998, 102, 1126-1132. [CrossRef]

34. Griffin, E.A.; Harrison, J.G.; McCormick, M.K.; Burghardt, K.T.; Parker, J.D. Tree diversity reduces fungal endophyte richness and diversity in a large-scale temperate forest experiment. Diversity 2019, 11, 234. [CrossRef]

35. Girometta, C.E.; Bernicchia, A.; Baiguera, R.M.; Bracco, F.; Buratti, S.; Cartabia, M.; Picco, A.M.; Savino, E. An italian research culture collection of wood decay fungi. Diversity 2020, 12, 58. [CrossRef]

36. Gargano, M.L.; Zervakis, G.I.; Isikhuemhen, O.S.; Venturella, G.; Calvo, R.; Giammanco, A.; Fasciana, T.; Ferraro, V. Ecology, phylogeny, and potential nutritional and medicinal value of a rare white "maitake" collected in a mediterranean Forest. Diversity 2020, 12, 230. [CrossRef]

37. Polemis, E.; Fryssouli, V.; Daskalopoulos, V.; Zervakis, G.I. Basidiomycetes associated with Alnus glutinosa habitats in Andros Island (Cyclades, Greece). Diversity 2020, 12, 232. [CrossRef]

38. Ogura-Tsujita, Y.; Tetsuka, K.; Tagane, S.; Kubota, M.; Anan, S.; Yamashita, Y.; Tone, K.; Yukawa, T. Differing life-history strategies of two mycoheterotrophic orchid species associated with leaf litter- and wood-decaying fungi. Diversity 2021, 13, 161. [CrossRef]

39. Dai, Y.C. A revised checklist of corticioid and hydnoid fungi in China for 2010. Mycoscience 2011, 52, 69-79. [CrossRef] 